\title{
Are memantine, methylphenidate and donepezil effective in sparing cognitive functioning after brain irradiation?
}

\author{
Rosa Wartena', Dieta Brandsma², José Belderbos ${ }^{3}$ \\ ${ }^{1}$ Amsterdam Universitair Medische Centra, Amsterdam 1081HV, The Netherlands. \\ 2Department of Neuro-oncology, The Netherlands Cancer Institute, Amsterdam 1066CX, The Netherlands. \\ ${ }^{3}$ Department of Radiation Therapy, The Netherlands Cancer Institute, Amsterdam 1066CX, The Netherlands.
}

Correspondence to: Dr. José Belderbos, Department of Radiation Therapy, The Netherlands Cancer Institute, Amsterdam 1066CX, The Netherlands. E-mail: j.belderbos@nki.nl

\begin{abstract}
How to cite this article: Wartena R, Brandsma D, Belderbos J. Are memantine, methylphenidate and donepezil effective in sparing cognitive functioning after brain irradiation? J Cancer Metastasis Treat 2018;4:59.

http://dx.doi.org/10.20517/2394-4722.2018.66
\end{abstract}

Received: 22 Oct 2018 First Decision: 19 Nov 2018 Revised: 6 Dec 2018 Accepted: 7 Dec 2018 Published: 26 Dec 2018

Science Editor: Lucyna Kepka Copy Editor: Cui Yu Production Editor: Huan-Liang Wu

\begin{abstract}
One strategy to reduce neurocognitive deterioration in patients after brain irradiation is the use of neuroprotective medication. To generate up-to date knowledge regarding neuroprotective agents we performed a systematic review on the clinical effectiveness of three agents that were reported to have neuroprotective characteristics: memantine, methylphenidate and donepezil. The use of memantine after brain irradiation showed a delay in cognitive deterioration, although at 24 weeks this did not reach significance $(P=0.059)$. Lack of significance is likely to be the result of the limited statistical power of $35 \%$ and memantine did show significant differences in secondary outcomes. The study on methylphenidate was not conclusive. Donepezil revealed significant differences in a few cognitive tests however no difference in global cognition was found. In addition, larger effects were observed in individuals with greater cognitive dysfunction prior to treatment.
\end{abstract}

Keywords: Memantine, donepezil, methylphenidate, brain irradiation, neuroprotection, whole brain irradiation, neuroprotective agent, lung cancer

\section{INTRODUCTION}

Radiotherapy is an important treatment modality for patients who suffer from primary brain tumours or brain metastases. Adverse effects of brain irradiation include fatigue, nausea, cognitive decline, ataxia

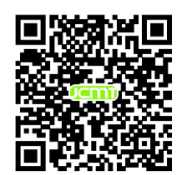


and alopecia. These side effects may be mild and transient, but can also be progressive and even persistent with structural brain damage on MRI scanning. Neurocognitive decline, especially memory dysfunction, is a major complaint following brain radiotherapy. In the United States, approximately 200,000 patients receive brain irradiation each year ${ }^{[1]}$. Due to both tumour progression and treatment, up to ninety percent of these patients experience cognitive dysfunction ${ }^{[1]}$. The treatment-related neurocognitive decline is poorly understood ${ }^{[2]}$, but causes a severe decline in the quality of life of these patients. Radiation injury is a multifactorial and complex event, characterized by vascular modification, inflammation, gliogenesis abnormalities and, when high-dose radiation is administered, even necrosis.

The incidence of radiation necrosis generally rises with an escalating radiation dose, fraction size and the administration of chemotherapy ${ }^{[3]}$. The precise mechanism of the neurotoxicity remains to be answered. However, two hypotheses (the vascular hypothesis and the glial hypothesis) explaining this neurocognitive decline have arisen ${ }^{[4]}$. The vascular hypothesis suggests that radiation induces vascular injury which leads to vascular inadequacy and so contributes to neurotoxicity. This neurotoxicity will eventually lead to neurocognitive decline. The degree of vascular inadequacy seems correlated to the extent of cognitive impairment ${ }^{[3]}$. The second hypothesis, the glial hypothesis, states that radiation therapy leads to a hold of gliogenesis because of a microglial inflammatory response induced by IL-6, inducing demyelinative necrosis. White matter networks are essential for cognitive function. By damaging these networks, as caused by demyelinative necrosis, cognitive impairment may occur ${ }^{[3]}$. However, in experimental animal studies, gliogenesis occurred to be fairly spared following radiation therapy, making this hypothesis less plausible. In contrast to this sparing of astrocytes and oligodendrocytes, a $97 \%$ reduction in "newborn" neurons was found in neurogenesis after brain irradiation ${ }^{[5]}$.

Whole brain radiotherapy (WBRT) or prophylactic cranial irradiation (PCI) exposes the whole cerebrum to a modest dose of radiation. Since the influence of brain irradiation on the long-term cognitive performance is a concern, several strategies, such as partial brain irradiation, hippocampal avoidance irradiation and the use of neuroprotective agents, aim to prevent or reduce radiation-induced cognitive deterioration ${ }^{[6]}$.

Memantine $e^{[7]}$, donepezil ${ }^{[8]}$ and methylphenidate ${ }^{[9]}$ have been widely studied in Alzheimer's disease and influence cognition. Memantine was reported to be effective in the treatment of moderate to severe Alzheimer's disease, whereas donepezil reduces the likelihood of progression of cognitive impairment at 12 months significantly $(P=0.004)$. In addition, these agents are suggested to be neuroprotective ${ }^{[6,10,11]}$, thereby possibly limiting cognitive deterioration after brain radiotherapy. This led to the following research question: are memantine, methylphenidate and donepezil successful in sparing cognitive functioning after cerebral radiotherapy-treatment?

A literature study was performed to determine the effect of memantine, methylphenidate and donepezil on the neurocognitive function of patients after partial or whole-brain radiotherapy.

\section{LITERATURE SEARCH STRATEGY}

A search in PubMed was conducted to evaluate the effect of memantine, methylphenidate and donepezil on cognition after brain-radiation therapy. In the Supplementary Table 1 you will find the details on the search strategy. The search date was January 2018. The articles had to be in English language. This search provided 58 articles. After applying the filters "human subjects" and "clinical trials", only eight articles were selected [Figure 1]. Each publication was carefully examined and identified to fit the research question based on the eligibility criteria. Including criteria for studies consisted of "human beings", "cranial irradiation therapy", "brain tumours or -metastases", the use of "memantine", "methylphenidate" or "donepezil" and "cognitive assessment". In addition, the trials had to be clinical trials, written in the English language. 


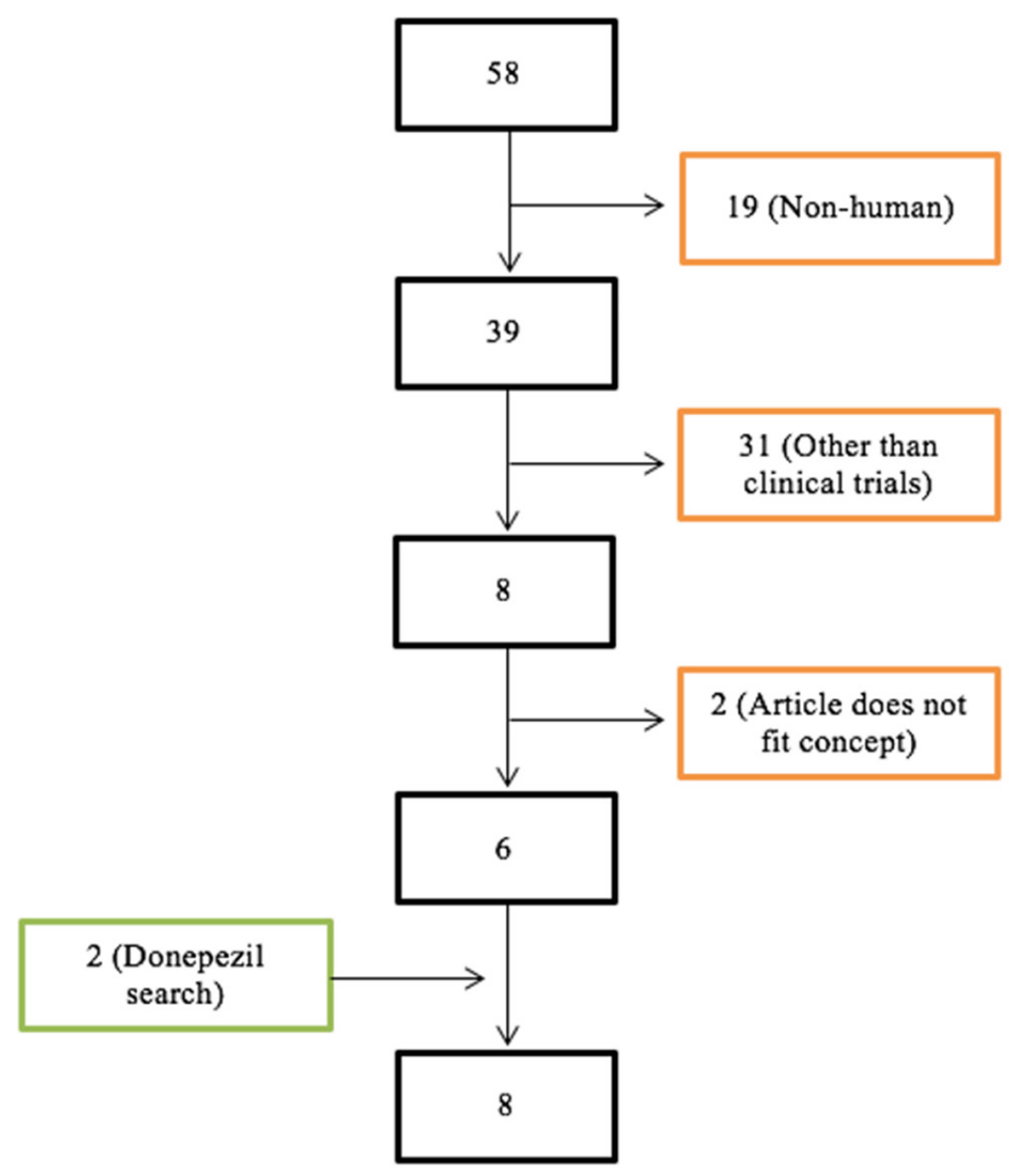

Figure 1. Flowchart of the PubMed search results

After the initial search, three additional searches were performed focussing on memantine, methylphenidate and donepezil. The search on donepezil revealed nine articles of which two were fitting the criteria. A total of eight articles were identified. The level of evidence of the individual studies was determined using Levels of Evidence by the Oxford Centre for Evidence-based Medicine ${ }^{[12]}$.

Data extraction was performed by studying the identified articles and interpreting the results focusing on the effect of memantine, methylphenidate and donepezil on sparing cognitive function after the cranial radiation therapy.

\section{MEMANTINE}

Memantine is a non-competitive NMDA-receptor antagonist which blocks the effects of excessive levels of glutamate that could cause neuronal dysfunction, which is currently used for the treatment of Alzheimer's disease and vascular dementia. For memantine, one large phase III clinical trial has been performed in patients with brain metastases [Table 1]. Brown et al. ${ }^{[6]}$ conducted a large placebo-controlled, double-blind, randomized trial of 508 subjects, to evaluate the potential beneficial effects of memantine on cognition in patients receiving WBRT. Memantine was administered in a daily dose of $20 \mathrm{mg}$, within three days after the start of WBRT, and appeared to be well tolerated. The primary endpoint of the study, delayed recall Hopkins Verbal Learning Test - Revised (HVLT-R) at 24 weeks, showed less decline however, this lacked statistical significance $(P=0.059)$. At 8 weeks the memantine arm indicated benefit; the median decline 
Table 1. Detailed information on study- and tumour type, neurocognitive tests performed, radiation treatment and level of evidence of the eight articles identified

\begin{tabular}{|c|c|c|c|c|c|c|}
\hline Author + Year & Agent + dose & Study type $+n$ & $\begin{array}{l}\text { Tumour } \\
\text { type }\end{array}$ & Neurocognitive tests & $\begin{array}{l}\text { Radiation therapy + } \\
\text { dose }\end{array}$ & $\begin{array}{l}\text { Level of } \\
\text { evidence }\end{array}$ \\
\hline 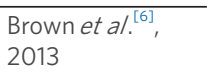 & $\begin{array}{l}\text { Memantine } \\
20 \mathrm{mg} / \mathrm{d}\end{array}$ & $\begin{array}{l}\text { Phase III } \\
n=508\end{array}$ & Brain metastases & HVLT-R, COWA & $\begin{array}{l}\text { WBRT } \\
37.5 \text { Gy }(15 \times 2.5 \text { Gy })\end{array}$ & $1 \mathrm{~b}$ \\
\hline $\begin{array}{l}\text { Rapp et al. }{ }^{[11]}, \\
2015\end{array}$ & $\begin{array}{l}\text { Donepezil } \\
5 \mathrm{mg} / \mathrm{d} \& \\
10 \mathrm{mg} / \mathrm{d}\end{array}$ & $\begin{array}{l}\text { Phase III } \\
n=198\end{array}$ & Brain tumours & $\begin{array}{l}\text { HVLT-R, mROCF, TMT, } \\
\text { COWA, DST, GP-D }\end{array}$ & $\begin{array}{l}\text { P/WBRT } \\
\text { U } 30 \mathrm{~Gy}\end{array}$ & $2 b$ \\
\hline $\begin{array}{l}\text { Shaw et al. }{ }^{[15]} \text {, } \\
2006\end{array}$ & $\begin{array}{l}\text { Donepezil } \\
5 \mathrm{mg} / \mathrm{d} \& \\
10 \mathrm{mg} / \mathrm{d}\end{array}$ & $\begin{array}{l}\text { Phase II } \\
n=35\end{array}$ & Brain tumours & $\begin{array}{l}\text { MMSE, TMT, DST, mROCF, } \\
\text { COWA, CVLT-2 }\end{array}$ & $\begin{array}{l}\text { P/WBRT } \\
\text { (dose not specified) }\end{array}$ & 4 \\
\hline $\begin{array}{l}\text { Correa et al. }{ }^{[16],} \\
2016\end{array}$ & $\begin{array}{l}\text { Donepezil } \\
5 \mathrm{mg} / \mathrm{d} \& \\
10 \mathrm{mg} / \mathrm{d}\end{array}$ & $\begin{array}{l}\text { Pilot } \\
n=24\end{array}$ & $\begin{array}{l}\text { Childhood brain } \\
\text { tumours }\end{array}$ & $\begin{array}{l}\text { DST, BTA, DST (WMS-III), } \\
\text { TMT, HVLT-R, BVMT-L }\end{array}$ & $\begin{array}{l}\text { RT/chemotherapy (dose } \\
\text { not specified) }\end{array}$ & 4 \\
\hline $\begin{array}{l}\text { Castellino et } a{ }^{[17]}, \\
2012\end{array}$ & $\begin{array}{l}\text { Donepezil } \\
5 \text { or } 10 \mathrm{mg} / \mathrm{d}\end{array}$ & $\begin{array}{l}\text { Pilot } \\
n=13\end{array}$ & Brain tumours & $\begin{array}{l}\text { D-KEFS, WRAML-2, CPT, } \\
\text { WISC-IV, Woodcock } \\
\text { Reading Mastery Test }\end{array}$ & $\begin{array}{l}\text { P/WBRT } \\
>23.5 \mathrm{~Gy}\end{array}$ & 4 \\
\hline $\begin{array}{l}\text { Jatoi et al. }{ }^{[18]}, \\
2005\end{array}$ & $\begin{array}{l}\text { Donepezil } \\
5 \mathrm{mg} / \mathrm{d} \& \\
10 \mathrm{mg} / \mathrm{d}\end{array}$ & $\begin{array}{l}\text { Phase III } \\
n=9\end{array}$ & SCLC & MMSE, BDS & $\begin{array}{l}\mathrm{PCl} \\
\text { (dose not specified) }\end{array}$ & 4 \\
\hline $\begin{array}{l}\text { Butler et al. }{ }^{[13]}, \\
2007\end{array}$ & $\begin{array}{l}\text { Methylphenidate } \\
5 \mathrm{mg} / \mathrm{d} \& \\
10 \mathrm{mg} / \mathrm{d} \& \\
15 \mathrm{mg} / \mathrm{d}\end{array}$ & $\begin{array}{l}\text { Phase III } \\
n=68\end{array}$ & $\begin{array}{l}\text { Brain tumours } \\
\text { and/or brain } \\
\text { metastases }\end{array}$ & MMSE & $\begin{array}{l}\text { P/WBRT } \\
\text { U } 25 \text { Gy } \\
(10 \times 1.8-3.0 \mathrm{~Gy})\end{array}$ & $2 b$ \\
\hline $\begin{array}{l}\text { Meyers et al. }{ }^{[14]}, \\
1998\end{array}$ & $\begin{array}{l}\text { Methylphenidate } \\
10 \mathrm{mg} / \mathrm{d} \& \\
20 \mathrm{mg} / \mathrm{d} \& \\
30 \mathrm{mg} / \mathrm{d}\end{array}$ & $\begin{array}{l}\text { Cohort } \\
n=30\end{array}$ & Brain tumours & $\begin{array}{l}\text { DST, HVLT, COWA, TMT, } \\
\text { grooved pegboard }\end{array}$ & $\begin{array}{l}\text { RT } \\
\text { (not specified) }\end{array}$ & 4 \\
\hline
\end{tabular}

SCLC: small cell lung cancer; WBRT: whole brain radiotherapy; P/WBRT: partial or whole brain radiotherapy; RT: radiotherapy; PCI: prophylactic cranial irradiation; HVLT-R: Hopkins Verbal Learning Test - Revised; TMT: trail making test; MMSE: Mini Mental Status Examination; BVMT: Brief Visuospatial Memory Test; WRAML-2: Wide Range Assessment of Memory and Learning scale 2; COWA: Controlled Oral Word Association Test; mROCF: modified Rey-Osterrieth complex figure; DST: digit span test; GP-D: grooved pegboarddexterity; CVLT-2: California Verbal Learning Test-2; BTA: brief test of attention; D-KEFS: Delis-Kaplan Executive Function System; CPT: Conners Continuous Performance Test; WISC-IV: Wechsler Intelligence Scale for Children-Fourth Edition; BDS: Blessed Dementia Scale

was -0.36 in the memantine arm and -0.72 in the placebo arm $(P=0.069)$. The time to cognitive decline, the rate of decline in memory using HVLT-R as well as executive function trail making test (TMT) part $\mathrm{B}$ and processing speed (TMT part A) were delayed favouring the memantine arm (HR 0.78, 95\% CI: $0.62-0.99, P=0.01$ ) as compared to the placebo. A $21 \%$ relative reduction was found in the probabilities of cognitive function failure at 24 weeks; the probability of cognitive function failure in the memantine arm was $53.8 \%$ whereas $64.9 \%$ was found in the placebo arm. Superior results were seen in the memantine arm for executive function at $8(P=0.008)$ and 16 weeks $(P=0.0041)$ and for processing speed $(P=0.0137)$ and delayed recognition $(P=0.0149)$ at 24 weeks. Moreover, time to cognitive decline was found to significantly favour the memantine arm. Lack of significance is likely to be the result of the limited statistical power of $35 \%$, because of a high dropout rate due to tumour progression and/or death. However, the almost significant finding could be beneficial in the long term for patients. The authors stated that the potential beneficial effects of memantine on cognitive function after WBRT may be more likely in patients with better prognostic factors or in the patients that respond well to radiation therapy.

\section{METHYLPHENIDATE}

Methylphenidate, mainly known as ritalin, was studied in clinical trials by both Butler et al. ${ }^{[13]}$ and Meyers et al. ${ }^{[14]}$. Butler et al. ${ }^{[13]}$ performed a double-blind, placebo-controlled randomized trial to determine the effects of methylphenidate (5-15 mg daily) on cognitive function in brain tumour patients receiving partial or WBRT to a dose of $>23.5$ Gray (Gy). The investigators did not find an advantage for the use of methylphenidate before WBRT in patients with primary brain tumours or metastatic brain tumours using the Mini Mental Status Examination (MMSE). Meyers et al. ${ }^{[14]}$ conducted a phase III trial on the effect of methylphenidate on 
cognition using an extensive test battery including memory recall and recognition and the trail making test (TMT) after radiotherapy treatment. The delivered radiation dose was not specified and only 30 patients with primary brain tumours were included. Each receiving 10-30 mg of methylphenidate twice daily for as long as the duration of the study which was not specified. Unlike Butler et al. ${ }^{[13]}$, this study indicated a significant improved function in psychomotor speed, memory, visual-motor function, executive function, motor speed and dexterity.

\section{DONEPEZIL}

Donepezil is an acetylcholinesterase inhibitor and is widely studied. Rapp et al. ${ }^{[11]}$ performed a phase III placebo-controlled trial in 198 subjects to determine whether donepezil improves cognitive function in primary brain tumour patients and patients with brain metastases treated with partial brain irradiation or WBRT receiving $\geq 30 \mathrm{~Gy}$. Patients received $5 \mathrm{mg}$ of donepezil for six weeks and $10 \mathrm{mg}$ of donepezil for 18 weeks after completing their course of radiation therapy (WBRT as well as partial brain irradiation). They found no difference in global cognition at 24 weeks. However, significant differences favouring donepezil were observed for recognition memory and motor speed and dexterity. The authors reported that the benefit from donepezil increased as the pre-treatment level of cognitive impairment increased. Shaw et al. ${ }^{[15]}$ performed a phase II clinical trial to evaluate cognitive functioning in partial or WBRT for patients with brain tumour after a 24-week donepezil treatment. Like Rapp et al. ${ }^{[11]}$ doses of 5 and $10 \mathrm{mg}$ daily were used. This study showed significant improvement in the following cognitive domains; attention/concentration, verbal memory and figural memory with a favourable trend for donepezil for verbal fluency. However, no change in global cognitive function was found, which is in line with the findings of Rapp et al. ${ }^{[11]}$, Correa et al. ${ }^{[16]}$ performed a pilot study including only 24 patients with brain tumours. Fifteen of these 24 patients received donepezil, after completion of therapy (80\% RT with or without chemotherapy, $20 \%$ received chemotherapy only), in the same quantities as Rapp et al. ${ }^{[11]}$ and Shaw et al ${ }^{[15]}$. This pilot study showed a significant postbaseline improvement in some aspects of attention; longest digit span forward, graphomotor speed, digit symbol subtest and Brief Visuospatial Memory Test - Revised for delayed recall. Improvements in other measurements were not conclusive or significant. Another pilot study was carried out by Castellino et al. ${ }^{[17]}$ to assess the toxicity and efficacy of donepezil in childhood brain tumour survivors. Thirteen children were enrolled into the study receiving a daily dose of 5 to $10 \mathrm{mg}$ of donepezil (depending on the child's weight). The median time from radiation therapy to study enrolment was extremely long: 4.7 years. This long interval possibly influences the effect of the donepezil treatment on cognitive sparing after cranial irradiation. This study showed improved as well as non-improved outcomes. Memory measured with the Wide Range Assessment of Memory and Learning scale was improved and a small effect in number/letter memory was found. Attention and concentration showed only non-significant effects. Other outcome measures like letter fluency and sorting tasks did not show significant improvement. Lastly, Jatoi et al ${ }^{[18]}$ conducted a double blind, placebo-controlled trial to test how donepezil $5 \mathrm{mg}$ /day (with dose escalation to $10 \mathrm{mg} /$ day after one month), and vitamin E, would affect the cognitive function of small-cell lung cancer patients after completing PCI. However, this study only accrued nine out of the calculated 104 patients and no results were available.

\section{DISCUSSION}

In this literature search, the neuroprotective effect of memantine, methylphenidate and donepezil was studied in patients with primary brain tumours, brain metastases or PCI treated with partial irradiation or WBRT. Memantine appeared to benefit cognitive outcomes after partial or WBRT, however the benefit did not reach significance at 24 weeks. Donepezil revealed significant differences in a few cognitive tests however the global cognition was not influenced. Methylphenidate showed indistinct results in the performed trials. Leaving the benefits of its use during brain irradiation unanswered. Overall, it is hard to conclude whether a possible neuroprotective agent we studied is effective in preserving cognitive function in patients receiving brain irradiation because of three reasons: in the reported studies, patient populations differ as 
well as the radiation treatment they have received and the neurocognitive tests varied which makes the exact difference between the three agents hard to determine. Another difficulty is that disease regression or progression interferes with neurocognitive improvement or deterioration. Our literature study identified eight papers of three studied agents. For memantine the evidence for delaying neurocognitive decline found in a single randomized trial that examined the effect of memantine on cognition in patients with brain metastases treated with WBRT was not statistically significant, although there was a trend that approached significance $(P=0.059 ; 35 \%$ statistical power). However, the secondary endpoints showed that memantine deferred the time to cognitive decline and also reduced the rate of this decline significantly. So on the long term, memantine could be beneficial for patients with brain tumours or brain metastases. Methylphenidate showed positive results for cognitive preservation in a small group of brain tumour patients undergoing brain irradiation. However, no advantage on MMSE was found in a double blind randomized trial between patients receiving methylphenidate and patients receiving placebo. Methylphenidate was studied in two clinical trials by Butler et al. ${ }^{[13]}$ and Meyers et al. ${ }^{[14]}$. The results were conflicting and the endpoints of the trials were different. Butler et al. ${ }^{[13]}$ used the MMSE whereas Meyers et al. ${ }^{[14]}$ used multiple, more sensitive cognitive tests. Butler et al ${ }^{[13]}$ found no advantage for prophylactic use of methylphenidate using the MMSE. The study was prematurely closed because of slow accrual, a high dropout rate and an interim analysis which did not show an effect for methylphenidate. Meyers et al. ${ }^{[14]}$ studied the use of methylphenidate on 30 brain tumour patients and found a significant improvement in the following cognitive domains; psychomotor speed, memory, visual-motor function, executive function, motor speed and dexterity. Besides the small sample size an important limitation of this study is the lack of long-term follow up. As a result, the observed differences could have been no more than just the result of chance findings. Rapp et al. ${ }^{[11]}$ conducted a placebo-controlled clinical trial in 198 brain tumour patients on cognition after the use of donepezil at 24 weeks. The improvement in cognitive function using multiple well-validated cognitive test-batteries occurred in both the donepezil-group and in the placebo-group. This means that there is an anti-tumour effect due to the irradiation and therefore improvement in cognitive function in both treatment arms. This trial emphasises the importance of a placebo-controlled trial to answer the question of neuroprotection. Without a placebo control group, an effect of the anti-cancer treatment on neurocognition could not be distinguished from an improvement due to the neuroprotective effects of the studied drug. Lastly, since the study was carried out in two academic medical centres (Wake Forest University Baptist Medical Centre and MD Anderson Cancer Centre), geographic diversity of the study population was achieved.

In accordance to the study by Rapp et al. ${ }^{[11]}$, the study by Shaw et al. ${ }^{[15]}$ showed significant improvement in attention/concentration, verbal memory and figural memory and a trend toward significance for verbal fluency. However, their study population was small and only MMSE was used. Unlike Rapp et al. ${ }^{[11]}$, the study by Shaw et al. ${ }^{[15]}$ clearly lacked a control-group.

The pilot studies carried out by Correa et al ${ }^{[16]}$ and Castellino et al. ${ }^{[17]}$ lacked a placebo-control group and both included extremely small study populations of respectively 24 and 13 subjects. The study by Castellino et al. ${ }^{[17]}$ included only childhood subjects, aged 8-17 years. Jatoi et al.$^{[18]}$ reported on a prematurely stopped trial after only nine patients were included and results are not available.

There are several limitations to our study. There has been heterogeneity in the selected patients: patients with primary as well as secondary brain tumours have been included. Besides, the type of radiation therapy differed: four out of eight studies included patients receiving partial and WBRT whereas one study included patients receiving WBRT and one study included patients only treated with PCI. Correa et al. ${ }^{[16]}$ even included patients receiving concurrent chemotherapy. Meyers et al. ${ }^{[14]}$ did not specify the type of irradiation used. In addition, the delivered radiation dose was not specified in four trials. Furthermore, there is no consensus on the optimal neurocognitive test battery to be used. In some trials only the MMSE was used. The HVLT-test was most commonly used, but no standard test was applied to determine the 
level of cognitive functioning. Also, neurocognitive decline may be due to tumour progression or based on neurotoxicity caused by the irradiation.

Besides, the drug administration started at different points in time. Most of the identified studies administered the study drugs after completion of the radiation therapy, but some studies administered the drug during the irradiation. In the trial by Castellino et al ${ }^{[17]}$ the median time from radiotherapy to enrolment of the study was 4.7 years (range 1.9-11.9 years) making it hard to determine whether donepezil would have any preventive effect on neurocognitive function. Another issue is the fact that a neuroprotective drug could interfere with the cytotoxic tumour effect of the irradiation if given concurrently.

A previously published review in 2014 by Attia et al. ${ }^{[19]}$ analysed different treatment options for radiationinduced cognitive decline. We included two more recent articles on donepezil; Rapp et al ${ }^{[11]}$ (2015) and Correa et al. ${ }^{[16]}$ (2016). Attia et al. ${ }^{[19]}$ reported a statistically significant improvement after administration of donepezil in several cognitive domains as based on the trial by Shaw et al. ${ }^{[15]}$. These domains include verbal memory, working memory, visual-motor and psychomotor performance and executive functioning. Importantly, in the trial by Shaw et al. ${ }^{[15]}$ (2006) no significant change was reported in global cognitive function or executive function.

The article on donepezil by Rapp et al. ${ }^{[11]}$ is a randomized placebo-controlled clinical trial in 198 subjects. This study did not show a global improvement in cognitive function, but differences in a few cognitive tests were shown.

Several trials are ongoing at the time of this literature study. One of these trials (NCT03342443) is a large ( $n$ = 240) randomized, double-blind, placebo-controlled trial carried out by the Sun Yat-Sen Memorial Hospital of Sun Yat-Sen University. This trial aims to determine the effect of memantine on cognitive function in patients with radiotherapy-related cognitive impairment due to head- and neck cancer. Another large $(n=$ 510) ongoing trial is the randomized phase III trial by NRG Oncology (NCT02360215). This trial aims to evaluate whether memantine and WBRT with or without hippocampal avoidance in patients with brain metastases can reduce neurocognitive decline.

\section{CONCLUSION}

In conclusion, the results of this systematic review on neurocognitive preservation in patients undergoing brain irradiation with memantine, methylphenidate or donepezil showed heterogeneity in the selected patients, the neurocognitive test used and the radiation treatment. Valuable clinical placebo controlled trials on neurocognitive preservation in patients undergoing brain irradiation are sparse. The results of this systematic review showed some evidence for the use of memantine to delay cognitive decline in patients undergoing brain irradiation. The results for methylphenidate remain inconclusive. Donepezil did show benefit in some domains although the global cognition was not influenced. Results from two ongoing trials on memantine (NCT03342443 and NCT02360215) are to be awaited.

\section{DECLARATIONS}

\section{Acknowledgements}

The authors acknowledge the important input of Sanne Schagen, Division of Psychosocial Research and Epidemiology, The Netherlands Cancer Institute, Amsterdam, The Netherlands.

\section{Authors' contributions}

Data collection and extraction, data analysis, writing: Wartena $\mathrm{R}$

Data analysis: Brandsma D

Data analysis, writing, editing: Belderbos J 


\section{Availability of data and materials}

Not applicable.

\section{Financial support and sponsorship}

None.

\section{Conflicts of interest}

All authors declared that there are no conflicts of interest.

\section{Ethical approval and consent to participate}

Not applicable.

\section{Consent for publication}

Not applicable.

\section{Copyright}

(c) The Author(s) 2018.

\section{REFERENCES}

1. Greene-Schloesser D, Moore E, Robbins ME. Molecular pathways: radiation-induced cognitive impairment. Clin Cancer Res 2013;19:2294300 .

2. Welzel G, Fleckenstein K, Schaefer J, Hermann B, Kraus-Tiefenbacher U, et al. Memory function before and after whole brain radiotherapy in patients with and without brain metastases. Int J Radiat Oncol Biol Phys 2008;72:1311-8.

3. Makale MT, McDonald CR, Hattangadi-Gluth JA, Kesari S. Mechanisms of radiotherapy-associated cognitive disability in patients with brain tumours. Nat Rev Neurol 2017;13:52-64.

4. Pereira Dias G, Hollywood R, Bevilaqua MC, da Luz AC, Hindges R, et al. Consequences of cancer treatments on adult hippocampal neurogenesis: implications for cognitive function and depressive symptoms. Neuro Oncol 2014;16:476-92.

5. Monje ML, Mizumatsu S, Fike JR, Palmer TD. Irradiation induces neural precursor-cell dysfunction. Nat Med 2002;8:955-62.

6. Brown PD, Pugh S, Laack NN, Wefel JS, Khuntia D, et al. Memantine for the prevention of cognitive dysfunction in patients receiving whole-brain radiotherapy: a randomized, double-blind, placebo-controlled trial. Neuro Oncol 2013;15:1429-37.

7. Rogawski MA, Wenk GL. The neuropharmacological basis for the use of memantine in the treatment of Alzheimer's disease. CNS Drug Rev 2003;9:275-308.

8. Petersen RC, Thomas RG, Grundman M, Bennett D, Doody R, et al. Vitamin E and donepezil for the treatment of mild cognitive impairment. N Engl J Med 2005;352:2379-88.

9. Rosenberg PB, Lanctôt KL, Drye LT, Herrmann N, Scherer RW, et al. Safety and efficacy of methylphenidate for apathy in Alzheimer's disease: a randomized, placebo-controlled trial. J Clin Psychiatry 2013;74:810-6.

10. Mulhern RK, Khan RB, Kaplan S, Helton S, Christensen R, et al. Short-term efficacy of methylphenidate: a randomized, double-blind, placebo-controlled trial among survivors of childhood cancer. J Clin Oncol 2004;22:4795-803.

11. Rapp SR, Case LD, Peiffer A, Naughton MM, Chan MD, et al. Donepezil for irradiated brain tumor survivors: a phase III randomized placebo-controlled clinical trial. J Clin Oncol 2015;33:1653-9.

12. Levels of evidence. BJU Int 2011;107:870.

13. Butler JM Jr, Case LD, Atkins J, Frizzell B, Sanders G, et al. A phase III, double-blind, placebo-controlled prospective randomized clinical trial of d-threo-methylphenidate HCI in brain tumor patients receiving radiation therapy. Int J Radiat Oncol Biol Phys 2007;69:1496-501.

14. Meyers CA, Weitzner MA, Valentine AD, Levin VA. Methylphenidate therapy improves cognition, mood, and function of brain tumor patients. J Clin Oncol 1998;16:2522-7.

15. Shaw EG, Rosdhal R, D’Agostino RB Jr, Lovato J, Naughton MJ, et al. Phase II study of donepezil in irradiated brain tumor patients: effect on cognitive function, mood, and quality of life. J Clin Oncol 2006;24:1415-20.

16. Correa DD, Kryza-Lacombe M, Baser RE, Beal K, DeAngelis LM. Cognitive effects of donepezil therapy in patients with brain tumors: a pilot study. J Neurooncol 2016;127:313-9.

17. Castellino SM, Tooze JA, Flowers L, Hill DF, McMullen KP, et al. Toxicity and efficacy of the acetylcholinesterase (AChe) inhibitor donepezil in childhood brain tumor survivors: a pilot study. Pediatr Blood Cancer 2012;59:540-7.

18. Jatoi A, Kahanic SP, Frytak S, Schaefer P, Foote RL, et al. Donepezil and vitamin E for preventing cognitive dysfunction in small cell lung cancer patients: preliminary results and suggestions for future study designs. Support Care Cancer 2005; 13:66-9.

19. Attia A, Page BR, Lesser GJ, Chan M. Treatment of radiation-induced cognitive decline. Curr Treat Options Oncol 2014;15:539-50. 